\title{
Arachnodactyly, aminoaciduria, congenital cataracts, cerebellar ataxia, and delayed developmental milestones
}

\author{
P. A. BHASKAR, K. JAGANNATHAN, AND K. VALMIKINATHAN \\ From the Institute of Neurology, Government General Hospital, Madras-3, India
}

SYNOPSIS Two male cousins are reported with arachnodactyly, selective aminoaciduria, congenital cataracts, cerebellar ataxia, and delayed developmental milestones, and a distant female relative with similar abnormalities. The syndrome is thought to be previously undescribed, though it has resemblances to Marinesco-Sịogren and Marfan's syndromes.

A syndrome characterized by arachnodactyly, selective aminoaciduria, congenital cataracts, cerebellar ataxia, and delayed developmental milestones was observed in two young boys who were first cousins. In certain respects the presentation was similar to that of the MarinescoSjögren syndrome but with a few additional clinical and biochemical features. In certain other respects it was suggestive of Marfan's syndrome. To our knowledge, such a combination of clinical and biochemical features has not been recorded hitherto.

\section{CASE REPORTS}

Two young male cousins, S., aged 18 years, and B. (MIN No. 6932/73), aged 12 years, were referred to us because of backwardness in intellect, cataracts since infancy, and unsteadiness in walking. Their relationship and the degree of consanguinity in their parents are brought out in the pedigree chart (Fig. 1).

CASE 1 (MIN No. 2549/68) S., the older of the cousins, was born full-term by natural delivery. His mother had not been seriously ill or exposed to radiation or known toxins during the pregnancy. He had been physically and mentally backward from early childhood. Speech was delayed till the third year, when he began to utter monosyllables. At the age of 2 years, he developed lenticular opacities in both eyes, which were 'needled' by an ophthalmologist. However, even after the vision had apparently improved, the expected gain in developmental mile-

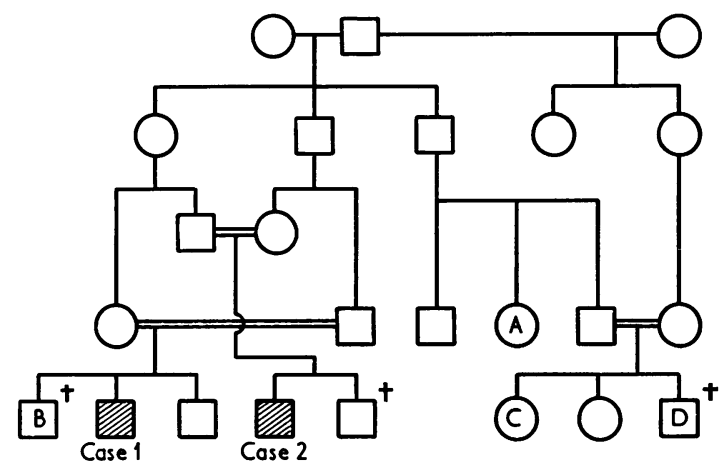

FIG. 1. Pedigree chart demonstrating the relationship between the two cases and the degree of consanguinity in their parentage. A: 43 year old woman said to have cataracts which developed at a very early age (not examined by us). B and D: infants (males) who were noticed to have bilateral cataracts and died at about the age of 3 years; cause of death not known. C: sixteen year old girl who was examined clinically by us. Bilateral after-cataracts, thin build, arachnodactyly, and Marfan-like features were noticed. Only urine available for tests.

stones was not forthcoming. He remained 'weak' in the lower limbs and 'clumsy' in the upper limbs. He had not attended school.

On examination, he was a thinly built individual with a head circumference of $53 \mathrm{~cm}$ (21 in) (Figs 2, 3, and 4). He had a poor vocabulary but good comprehension. The volume of his voice was low and speech 


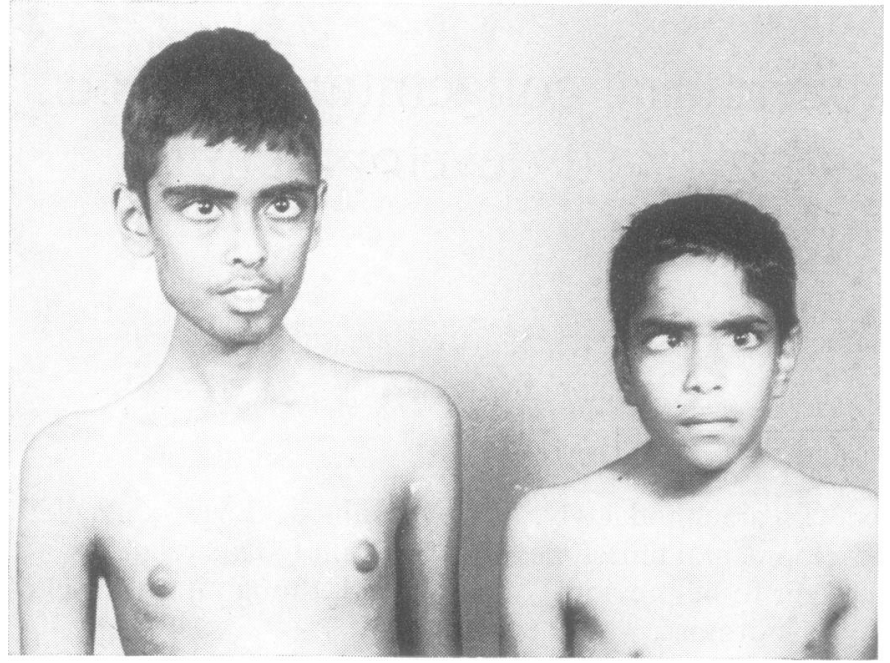

FIG. 2. The first cousins. Left: case 1; right: case 2 , showing the squint in both and gynaecomastia in case 1.

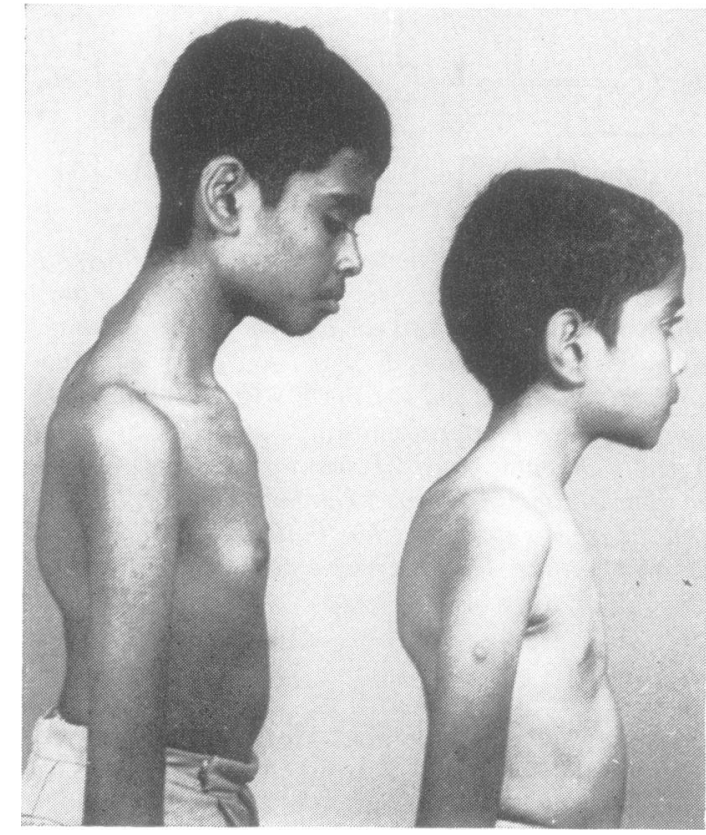

FIG. 3. Cases 1 and 2. Lateral view showing dorsal kyphosis, flat chest, thin build, and the gynaecomastia in case 1 .
FIG. 4. Cases 1 and 2. The thin build, Marfanoid features, and the normally developed external genitalia are shown.

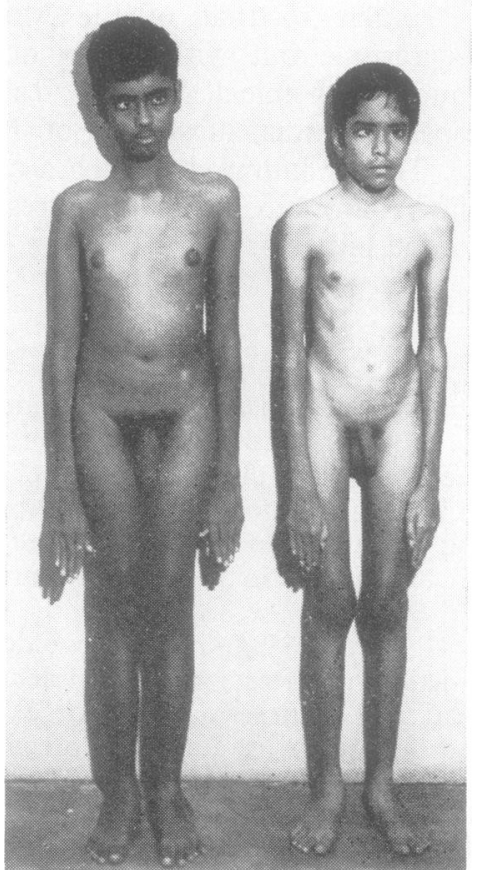




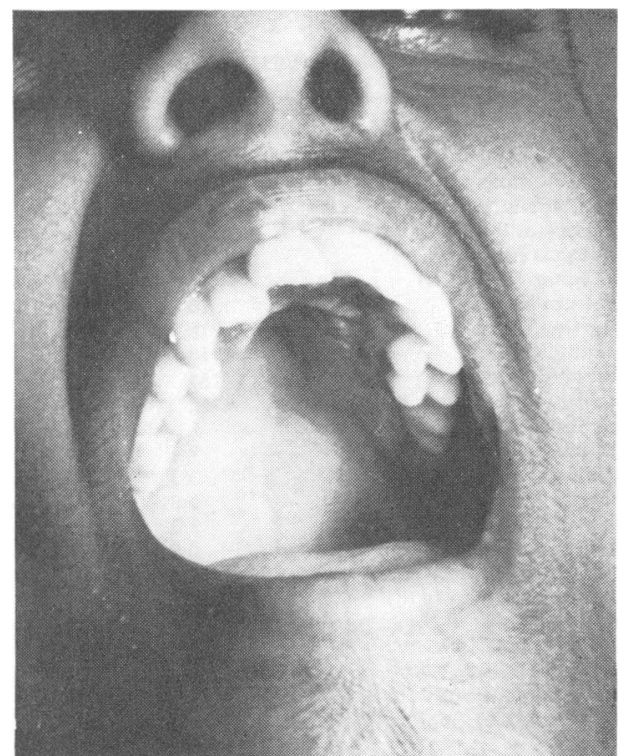

FIG. 5. Case 1. High arched palate. syllables were split in a staccato way. Intelligence quotient tested on the Binet-Kamath scale gave a mental age of 5 years. The visual acuity was poor $(1 / 60)$ in both eyes. An 'after-cataract' had developed in the right eye. The pupils were normal in size and reaction and the appearance of the left ocular fundus was normal. A concomitant squint was evident on relaxed forward gaze (Fig. 2). The intraocular tension was normal. The extraocular movements were full with coarse nystagmus on either horizontal gaze. The limbs were hypotonic with normal power in the upper limbs and MRC grade 4/5 power in both lower limbs. Finger-nose-finger and heel-knee incoordination were evident on both sides with mild truncal ataxia and intense gait ataxia, necessitating support while walking. The tendon jerks were quite brisk with flexor plantar response bilaterally. Sensory appreciation and sphincter control were intact.

The other characteristic features noticed in this young man were the thick bushy eyebrows and eyelashes (Fig. 2), flat feet (Fig. 6), mild upper dorsal kyphosis (Fig. 3), sabre tibiae, arachnodactyly (Fig. 7), high arched palate (Fig. 5), and bilateral gynaeco-

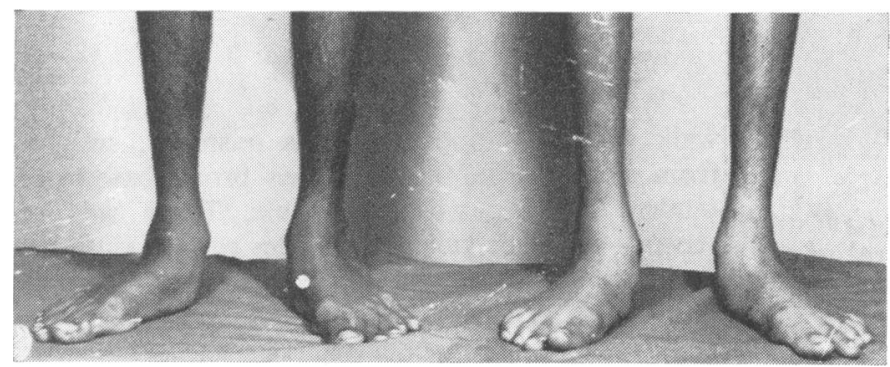

FIG. 6. Cases 1 and 2. Flat feet.

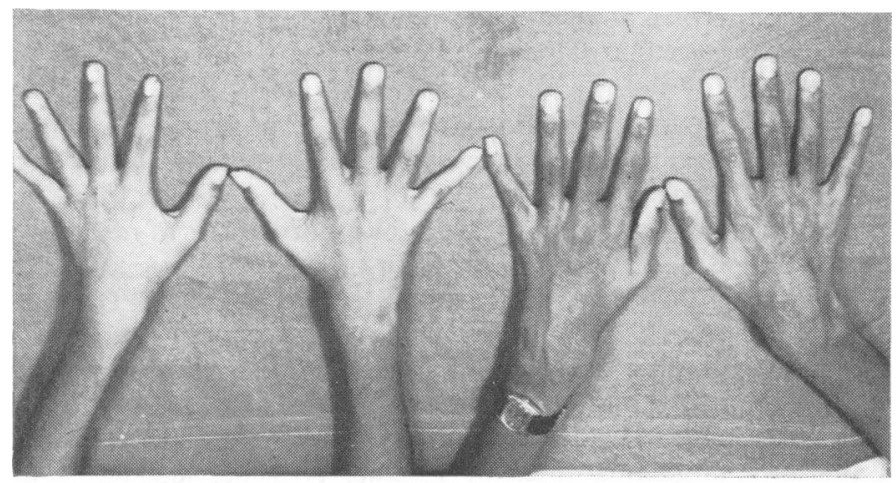

FIG. 7. Cases 1 and 2. Arachnodactyly. 
mastia (Fig. 3). His secondary sexual characters were well developed (Fig. 4). His height measured $152 \mathrm{~cm}$, span $163 \mathrm{~cm}$, and crown to symphysis pubis $73 \mathrm{~cm}$. Liver and spleen were not enlarged.

CASE 2 (MIN No. 6932/73) B., the younger of the two cousins, was aged 12 years at the time of examination. He was also born by natural delivery after a full-term gestation. Until the age of 4 years, he was not able to sit up without support. He developed cataract at the age of $1 \frac{1}{2}$ years. Two years later, an ophthalmologist 'needled' the cataracts and some return of vision resulted. He was put to school only at the age of 10 years but discontinued two years later as he was unable to grasp the lessons taught. He continued to remain unsteady while walking and attempting to write.

On examination, he appcared to be more chserful

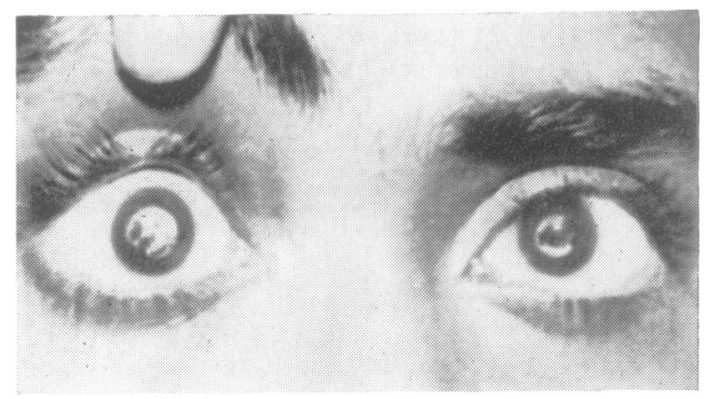

FIG. 8. Case 2. Dense after-cataract in the right eye and capsular remnants of 'needling procedure' in the left eye. The thick eyebrows and long eyelashes are also seen.

and cooperative than his elder cousin; it was possible to communicate with him by conversation. Speech was normal. Intelligence as tested by the BinetKamath method placed his mental age at the 8 year level. The visual acuity in the left eye was $6 / 18$ and only hand movements could be perceived by the right eye. A prominent convergent squint was seen (Fig. 2). Extraocular movements were full with coarse nystagmus on looking to either side. In the right eye a dense after-cataract had developed which had occupied the entire pupillary aperture, while the left eye contained the capsular remnants of the previous needling procedure (Fig. 8).

All four limbs were hypotonic and exhibited intention tremor. The tendon jerks were brisk with flexor plantar responses bilaterally. $\mathrm{He}$ was able to
TABLE 1

LABORATORY INVESTIGATIONS

\begin{tabular}{|c|c|c|}
\hline & Case I & Case 2 \\
\hline \multicolumn{3}{|l|}{ Blood and serum } \\
\hline Haemoblobin (g/dl) & $10 \cdot 6$ & $9 \cdot 8$ \\
\hline Erythrocytes (million $/ \mathrm{mm}^{3}$ ) & $3 \cdot 2$ & 3.4 \\
\hline Leucocytes (per $\mathrm{mm}^{3}$ ) & 8,600 & 9,400 \\
\hline Diff. count $(P / L / E / M)$ & $54 / 36 / 8 / 2$ & $48 / 44 / 8 / 0$ \\
\hline $\operatorname{ESR}(\mathrm{mm} / \mathrm{hr})$ & 10 & 8 \\
\hline Sugar (mg/dl) & 78 & 70 \\
\hline Urea (mg/dl) & 18 & 20 \\
\hline Cholesterol (mg/dl) & 185 & 155 \\
\hline Alkaline phosphatase (KA units) & 12 & $7 \cdot 6$ \\
\hline Acid phosphatase (KA units) & 1 & 0.7 \\
\hline Calcium (mg/dl) & $9 \cdot 4$ & $10 \cdot 2$ \\
\hline Phosphorus (mg/dl) & $3 \cdot 3$ & $3 \cdot 8$ \\
\hline Total proteins $(\mathrm{g} / \mathrm{dl})$ & $6 \cdot 3$ & 6.9 \\
\hline Albumin (g/dl) & $3 \cdot 2$ & $3 \cdot 7$ \\
\hline Alpha globulin (g/dl) & 0.9 & 0.9 \\
\hline Beta globulin $(\mathrm{g} / \mathrm{dl})$ & 0.6 & 0.7 \\
\hline Gamma globulin (g/dl) & 1.6 & $1 \cdot 6$ \\
\hline Sodium $(\mathrm{mEq} / \mathrm{l})$ & 140 & 139 \\
\hline Chloride (mEq/l) & 99 & 104 \\
\hline Potassium (mEq/1) & $3 \cdot 1$ & $3 \cdot 6$ \\
\hline pH of arterial blood & $7 \cdot 34$ & $7 \cdot 22$ \\
\hline Serum creatinine $(\mathrm{mg} / \mathrm{dl})$ & 0.80 & 0.74 \\
\hline \multicolumn{3}{|l|}{ Urine } \\
\hline 17-ketosteroids (mg per $24 \mathrm{hr}$ ) & $8 \cdot 4$ & $5 \cdot 6$ \\
\hline Calcium (mg per $24 \mathrm{hr}$ ) & 112 & Not done \\
\hline Phosphorus (mg per $24 \mathrm{hr}$ ) & 943 & Not done \\
\hline Protein (mg per $24 \mathrm{hr}$ ) & 98 & 88 \\
\hline pH & $5 \cdot 78$ & 5.90 \\
\hline Creatinine (mg per $24 \mathrm{hr}$ ) & 682 & 540 \\
\hline
\end{tabular}

walk without support but was unsteady, swayin from side to side. The gait was broad based ant $\overrightarrow{0}$ tandem walking was impossible. There was no sensory deficit or lack of sphincter control.

On general examination, he was also of asthenic build (Fig. 4) with a dorsal kyphosis (Fig. 3), flat chest (Fig. 3), arachnodactyly (Fig. 7), flat feet (Fig. 6), high arched palate, thick eyebrows, and long eyelashes (Fig. 8). He had sparse pubic hair and a normally developed phallus and testes (Fig. 4). His height measured $142 \mathrm{~cm}$, span $150 \mathrm{~cm}$, and the crown to symphysis pubis $65 \mathrm{~cm}$. Liver and spleen were not palpable.

LABORATORY INVESTIGATIONS The results of the routine laboratory investigations are listed in Table 1 .

Urine screening tests for inborn errors of metabol- $\delta$ ism (Benedict's test, cyanide-nitroprusside test, ₹ CTAB test, ferric chloride test, and DNPH test) 0 were normal. However, two-dimensional chromatographic study of the urinary amino acids on paper using butanol:acetic acid:water $(40: 7: 5, \mathrm{v} / \mathrm{v})$ and phenol: water $(4: 1, \mathrm{v} / \mathrm{v})$ systems showed evidence for $O$ large quantities of glycine, tyrosine, leucine, and $\tilde{O}$ 
TABLE 2

CONCENTRATION OF URINARY AMINO ACIDS

\begin{tabular}{lcccc}
\hline & Case 1 & Case 2 & Case 3† & Control \\
\hline Cystine & 0.15 & 0.14 & 0.14 & 0.13 \\
Glycine & 0.85 & 0.90 & 0.72 & 0.12 \\
Histidine & 0.70 & 0.48 & 0.32 & 0.16 \\
Leucine & 0.40 & 0.17 & 0.30 & 0.02 \\
Phenylalanine & 0.04 & 0.05 & 0.04 & 0.06 \\
Proline & 0.06 & 0.06 & 0.05 & 0.06 \\
Serine & 0.05 & 0.06 & 0.05 & 0.04 \\
Threonine & 0.12 & 0.11 & 0.11 & 0.11 \\
Tryptophane & 0.02 & 0.03 & 0.03 & 0.02 \\
Tyrosine & 0.83 & 0.67 & 0.74 & 0.03 \\
Valine & 0.03 & 0.02 & 0.03 & 0.02 \\
& & & & \\
\hline
\end{tabular}

* Expressed as aminoacid/creatinine/24 hr.

+ Case 3 refers to the 16 year old relative of the other two cases marked ' $C$ ' in the pedigree chart (Fig. 1).

$\ddagger$ Control: unrelated boy aged 12 years.

histidine in the urine of both cases. (The method adopted for quantitation was that described by Varley, 1967). Analysis of the aminoacids in the patients' sera was also conducted. The serum and urine of a 12 year old boy (control) was analysed for the same aminoacids (Tables 2 and 3 ).

OTHER INVESTIGATIONS In both cases, radiographs of the skull and chest were normal, while those of the hand proved the presence of arachnodactyly (Sinclair et al., 1960). Metacarpal index in case 1

TABLE 3

SERUM LEVELS OF AMINOACIDS EXCRETED IN EXCESS IN URINE $(\mathrm{mg} / 100 \mathrm{ml})$

\begin{tabular}{llll}
\hline & Case 1 & Case 2 & Control* $^{*}$ \\
\hline Glycine & $2 \cdot 1$ & 1.4 & 1.8 \\
Histidine & 1.4 & $1 \cdot 7$ & 1.4 \\
Leucine & 2.4 & $2 \cdot 1$ & $2 \cdot 5$ \\
Tyrosine & 1.2 & 1.8 & 1.3 \\
Creatinine & 0.80 & 0.74 & 0.66 \\
\hline
\end{tabular}

* Control: boy aged 12 years.

was $9 \cdot 4$, and in case 2 it was $9 \cdot 5$ (normal range: $5 \cdot 4$ to 7.9). Buccal smear study in both of them proved to be chromatin negative with karyotype $22+X Y$ with no structural abnormalities of the chromosomes. In both cases the electroencephalograph and electrocardiogram were within normal limits. Electrophoretic patterns of serum lipoproteins were normal.
Other family studies A distantly related 16 year old girl (case $\mathrm{C}$ in Fig. 1) also has bilateral aftercataracts, thin build, arachnodactyly, and Marfanlike features. Only urine was available for testing but showed the same selective aminoaciduria as the probands (Table 2). Unfortunately, the living sibling of case 1 is not available for study.

\section{DISCUSSION}

Both cases satisfied the criteria for the MarinescoSjögren syndrome (Marinesco et al., 1931; Sjögren, 1950)—namely, oligophrenia, cerebellar ataxia, and congenital cataracts. Some of the other findings in our cases were also recorded by other authors: flat feet were observed by Richards (1950); brisk tendon jerks and equivocal plantar responses were recorded by Dureux et al. (1958) and Sjögren (1950); scoliosis and kyphoscoliosis by Garland and Moorhouse (1953); and ocular squint by Alter et al. (1962). Many other clinical features additional to the basic Marinesco-Sjögren syndrome are on record. These include prominent ears (Doḡulu and Mutlu, 1957); pes cavus (Dureux et al., 1958); genu valgum, deformed fingers, and short stature (MacGillivray, 1957); anomalies of sex organs (Freycon and Freycon, 1965); dental anomalies, hypopituitarism, and retinitis pigmentosa (Carrieri and Di Gennaro, 1965); myopathic features (Alter and Kennedy, 1968), etc.

Accepting our cases as basically examples of the Marinesco-Sjögren syndrome, there are some additional observations: (1) arachnodactyly with high arched palate and other skeletal abnormalities reminiscent of Marfan's syndrome, and (2) presence of selective aminoaciduria (glycine, leucine, histidine, and tyrosine). These findings could be considered coincidental, but, in view of their consistent presence in more than one sib, appear less likely to be so.

In Marfan's syndrome, which our cases resembled morphologically, the presence of specific aminoacidurias, cerebellar features, and lenticular opacities have not been recorded. Again, the negative cyanide-nitroprusside urine test excluded homocystinuria, which sometimes presents clinically as a Marfan-like syndrome (Dunn et al., 1966).

Aminoaciduria, cataracts, and oligophrenia 
constitute the oculocerebrorenal syndrome of Lowe (Lowe et al., 1952). Cerebellar dysfunction, nystagmus, intention tremor (McCance et al., 1960), and rachitic features have also been recorded in this clinical entity. However, the absence of the following characteristic features of this syndrome does not favour the diagnosis of Lowe syndrome in our cases: (1) hypotonia and areflexia (Chutorian and Rowland, 1966); (2) renal tubular acidosis (Sagel et al., 1970); (3) aminoaciduria, involving most of the common amino-acids (Schoen and Young, 1959).

The occurrence of aminoaciduria in cases of the Marinesco-Sjögren syndrome is unknown. However, involvement of the kidney has been recorded in literature. Crome et al. (1963) described a syndrome resembling a combination of the Marinesco-Sjögren and Lowe's syndromes presenting with congenital cataracts, renal tubular necrosis, and encephalopathy in two sisters. Similarly D'Angelo and Ahlheid (1968) discovered deposits of a lipid substance in the lungs, kidney, liver, and spleen at necropsy in a case of Marinesco-Sjögren syndrome. But selective aminoaciduria was not described in either of these reports.

Histidine, leucine, and tyrosine share a common transport mechanism with other amino acids like phenylalanine, valine, threonine, etc. In the present study, the excretion of phenylalanine, threonine, serine, cystine, proline, valine, and tryptophane was well within normal limits, indicating a selective defect in the renal tubular transport mechanism. This defect seems also to affect the transport of glycine, which usually shares a common transport mechanism with proline and hydroxyproline. The explanation for this selective transport defect resulting in the excretion of this combination of aminoacids remains obscure.

It is suggested that this syndrome, characterized by arachnodactyly, selective aminoaciduria, congenital cataracts, cerebellar ataxia, and delayed developmental milestones which was observed in a few members of a family, is a genetically determined disorder probably transmitted in the autosomal recessive manner. The condition could well be an instance of a hitherto undescribed disease with features common to Marfan's and the Marinesco-Sjögren syndrome.
The authors are grateful to Professor B. Ramamurthi, Head of the Institute of Neurology and the Superintendent, Government General Hospital, for permitting them to publish an account of these patients.

\section{REFERENCES}

Alter, M., and Kennedy, W. (1968). Marinesco-Sjögren syndrome. Hereditary cerebello-lental degeneration with mental retardation. Minnesota Medicine, 51, 901-906.

Alter, M., Talbert, O. R., and Croffead, G. (1962). Cerebellar ataxia, congenital cataracts, and retarded somatic and mental maturation. Report of cases of Marinesco-Sjögren syndrome. Neurology (Minneap.), 12, 836-847.

Angelo, C. D', and Ahlheid, A. (1967). Sindrome di Marinesco-Sjögren. Due casi clinici con un reperto neuropatologico. Lavoro Neuropsichiatrico, 40, 291-318.

Carrieri, G., and Di Gennaro, C. (1965). Sulla sindrome di Marinesco-Sjögren. Osservazione di due casi familiari. Giornale di Psichiatria e di Neuropatologia, 93, 667-681.

Chutorian, A., and Rowland, L. P. (1966). Lowe's syndrome. Neurology (Minneap.), 16, 115-122.

Crome, L., Duckett, S., and Franklin, A. W. (1963). Congenital cataracts, renal tubular necrosis and encephale $\mathcal{W}$ pathy in two sisters. Archives of Diseases in Childhood, 3\$ 505-515.

Dogulu, S., and Mutlu, N. (1957). Iki kardești konjenitæॄ $\vec{N}$ katarakt, spinoserebellar ataksia ve oligofrenia. Deniz T Bülteni, 3, 1-4.

Dunn, H. G., Perry, T. L., and Dolman, C. L. (1966) Homocystinuria. A recently discovered cause of mentat defect and cerebrovascular thrombosis. Neurolog (Minneap.), 16, 407-420.

Dureux, J. B., Cordier, J., Ziza, P., and Tridon, P. (195\$. Hérédo-ataxie, cataracte et oligophrénie (syndrome Marinesco-Sjögren). Revue Neurologique, 98, 777-781.

Freycon, F., and Freycon, M. T. (1965). Le syndrome de $\vec{\theta}$ Marinesco-Sjögren. Pediatrie, 20, 101-103.

Garland, H., and Moorhouse, D. (1953). An extremely rare recessive hereditary syndrome including cerebellar ataxia, oligophrenia, cataract, and other features. Journal of Neurology, Neurosurgery, and Psychiatry, 16, 110-116.

Lowe, C. U., Terrey, M., and MacLachlan, E. A. (1952). Organic-aciduria, decreased renal ammonia production, $\mathbb{D}$ hydrophthalmos, and mental retardation: a clinical entity. American Journal of Diseases of Children, 83, 164- $\overline{\bar{O}}$ 184.

McCance, R. A., Matheson, W. J., Gresham, G. A., and Elkington, J. R. (1960). The cerebro-ocular-renal dystro-z phies: a new variant. Archives of Disease in Childhood, 35, 240-249.

MacGillivray, R. C. (1957). Oligophrenia, cerebellar ataxia and cataract. The syndrome of Marinesco-Garland. American Journal of Mental Deficiency, 61, 719-724.

Marinesco, G., Draganesco, St, and Vasiliu, D. (1931). Nouvelle maladie familiale caractérisée par une cataracte congénitale et un arrêt du développement somato-neuro-? psychique. L'Encéphale, 26, 97-109.

Sagel, I., Ores, R. O., and Yuceoglu, A. M. (1970). Renal function and morphology in a girl with oculocerebrorenalo syndrome. Journal of Pediatrics, 77, 124-127.

Santa, T., Araki, S., Terao, A., and Kuroiwa, Y. (1969). N Marinesco-Sjögren syndrome: clinical study of two cases 
in a family (Japanese). Brain and Nerve (Tokyo), 21, 821826.

Schoen, E. J., and Young, G. (1959). "Lowe's syndrome". Abnormalities in renal tubular function in combination with other congenital defects. American Journal of Medicine, 27, 781-792.

Sinclair, R. J. G., Kitchin, A. H., and Turner, R. W. D.
(1960). The Marfan syndrome. Quarterly Journal of Medicine, 29, 19-46.

Sjögren, T. (1950). Hereditary congenital spinocerebellar ataxia accompanied by congenital cataract and oligophrenia. Confinia Neurologica, 10, 293-308.

Varley, H. (1967). Practical Clinical Biochemistry, 4th edn, p. 223. Heinemann: London. 